\title{
RELATOS DE ATIVIDADES DE CONSCIENTIZAÇÃO E EDUCAÇÃO AMBIENTAL SOBRE O DESTINO CORRETO DOS RESÍDUOS SÓLIDOS EM SÃO BORJA - RS
}

\author{
Valmor Rhoden \\ Universidade Federal do Pampa \\ vrhoden6@gmail.com
}

\author{
Luiza Bellinazo Ribeiro \\ Universidade Federal do Pampa \\ luizabribeiro@live.com
}

Saionara Eliane Salomoni

Universidade Estadual do Rio Grande do Sul saiosalomoni@hotmail.com

Resumo

A degradação ambiental decorrente da poluição dos recursos naturais através dos resíduos sólidos urbanos é hoje um problema que afeta cada vez mais a população. O objetivo deste projeto foi conscientizar parte da população da cidade de São Borja, Rio Grande do Sul, sobre a destinação correta do lixo e a importância da separação do lixo e seu destino ideal, para que assim, cada um faça sua parte nesse processo, tendo conhecimento da atual situação da cidade. Além da pesquisa bibliográfica, utilizamos o relato de experiência como amparo para a elaboração deste artigo. As ações de conscientização foram realizadas no ano de 2016, apresentando o projeto à comunidade. É importante fazermos a nossa parte como Universidade, despertar nas pessoas a ideia de que cada um precisa fazer a sua função para que tenhamos menos agressões ao meio ambiente.

Palavras-chave: Resíduos Sólidos. Conscientização Ambiental. Educação Ambiental.

\section{REPORTS OF CONSCIENTIZATION AND ENVIRONMENTAL EDUCATION ACTIVITIES ON THE CORRECT DESTINATION OF SOLID WASTE IN SÃO BORJA - RS}

\begin{abstract}
The environmental degradation resulting from the pollution of natural resources through urban solid waste is now problem that affect the population more and more. The objective of this project was to raise awareness of the population of the city of São Borja on the correct destination of garbage and the importance of the separation of garbage and its ideal destination, so that each one can play a part in this process, being aware of the current situation of City. In addition to bibliographical research, we used the experience report as support for the elaboration of this article. The project was carried out in the year 2016. It is important to do our part as a university, to awaken in people the idea that each one must do his or her job so that we have less aggression on the environment.
\end{abstract}

Keywords: Solid Waste. Environmental Awareness. Environmental Education.

\section{ACTIVIDADES DE SENSIBILIZACIÓN Y EDUCACIÓN AMBIENTAL INFORMES SOBRE EL DESTINO CORRECTO DE RESIDUOS SÓLIDOS EN SAN BORJA - RS}

\begin{abstract}
Resumen
La degradación ambiental de la contaminación de los recursos naturales a través de los residuos sólidos urbanos, es hoy un problema que afecta la población cada vez más. El objetivo de este proyecto era aumentar la conciencia de la población de San Borja en la eliminación adecuada de basura y la importancia de la separación de residuos y su destino ideal, por lo que cada uno haga su parte en este proceso, siendo conscientes de la situación actual ciudad. Además de la literatura, se utiliza el informe de experiencia como apoyo para la preparación de este artículo. El proyecto se llevó a cabo en 2016, acciones fueron diseñados, la sensibilización y la presentación del proyecto a la comunidad. Es importante hacer nuestra parte como una universidad, despertar en la gente la idea de que cada uno tiene que hacer su función a tener menos daño al medio ambiente.

Palabras clave: Residuos Sólidos. La Conciencia Ambiental. La Educación Ambiental.
\end{abstract}


Relatos de atividades de conscientização e educação ambiental sobre o destino correto dos resíduos sólidos em São Borja - RS

\section{INTRODUÇÃO}

A questão de sustentabilidade ambiental e do lixo que produzimos está sendo cada vez mais debatida na sociedade, pois isso pode afetar em grande proporção a saúde humana e ao meio ambiente em que vivem. Loureiro, Layrargues e Castro (2009) destacam a importância de despertar na sociedade a conscientização de seus atos e os desafios que isso resulta. Devido ao crescimento populacional nacional, a quantidade de resíduos produzidos está aumentando de forma absurda. Segundo a Associação Brasileira de Empresas de Limpeza Pública e Resíduos Especiais (ABRELPE), a produção de resíduos sólidos no país é cinco vezes maior que o crescimento populacional. Assim, é de suma importância esclarecer às crianças desde os anos iniciais de que o lixo é um dos grandes problemas que atinge a sociedade.

Como já apontou uma pesquisa feita por Duarte (2002, p.152-153) “apenas 38\% dos brasileiros se consideravam integrantes do meio ambiente." Isto significa que para a maioria dos brasileiros, meio ambiente é apenas o meio natural, do qual estão excluídos, assim como está excluído o seu habitat. Diante de tantas agressões que vem sofrendo o meio ambiente, o projeto nasceu com o principal intuito de conscientizar a comunidade são-borjense, no estado do Rio Grande do Sul, sobre a importância da separação do lixo e seu destino ideal. Iniciaram-se ações no primeiro semestre de 2016, onde diretamente foi apresentado e executado junto à comunidade ações dinâmicas para conscientizá-la sobre a importância de cuidar do meio ambiente. A conscientização é um processo de comparação do ser humano com a realidade a fins de assimilá-la. A conscientização então, não é nada a mais que ir além de uma consciência incauta, na qual se deve destacar o poder que cada um pode tomar para transformar o mundo em algo melhor.

Para Freire (1980), conscientização entende-se como o desenvolvimento das descobertas do ser humano, onde se buscam respostas para suas interrogações e até mesmo observações. A consciência humana está relacionada ao mundo real, ou ao seu cotidiano, é por esse motivo que na maioria das vezes o ser humano busca livrar-se dos problemas que coíbem que se tenha uma boa visão do mundo cotidiano. A conscientização é um processo que exige comprometimento dos organizadores e trabalho diante da comunidade.

Por conseguinte, conscientizar significa conquistar sua própria liberdade. É a partir de então que o ser humano percebe tudo que o cerca. Pois, como já sabemos a consciência humana está ligada ao mundo real. O que torna a humanidade consciente de todas as 
Relatos de atividades de conscientização e educação ambiental sobre o destino correto dos resíduos sólidos em São Borja - RS

atividades de pessoa para pessoa e, desta maneira, o homem conhece suas próprias ações. Duarte (2002, p. 151) ressalta que:

\footnotetext{
Numa sociedade democrática, são as pessoas que moldam seus governos, e não o contrário. Mas, para que isso ocorra é preciso que estejamos conscientes, que é mais do que estarmos informados, embora informação seja pré-suposto para o processo de conscientização. Enquanto não assumirmos, de verdade, o nosso papel de cidadãos, nada vai mudar.
}

O desafio que se tem é fazer com que a população se entenda inserida e que proteger o meio ambiente traz benefícios para ela.

\section{CONSCIENTIZAÇÃO AMBIENTAL}

O ser humano constantemente teve a necessidade dos recursos que o meio ambiente produz e já cogitou pensar que os recursos eram infinitos. A conscientização ambiental é a criação de um juízo crítico em relação aos prejuízos sofridos pelo meio ambiente devido à sua exploração sem cuidados que deveria ter pelos seres humanos desde o princípio até os dias de hoje. Por esse motivo, existem normas ambientais que ganham cada dia mais importância: produção com utensílios reciclados, energia com recursos sustentáveis, entre outras. Garcia (2009) relata a importância de uma organização em diminuir o impacto sobre o meio ambiente quando produz um produto. E fazer isso, pode significar antes de tudo, uma oportunidade de estratégia para uma gestão efetiva.

De acordo com a afirmação de Garcia (2009), entende-se que a sociedade tem uma necessidade de melhorar a qualidade ambiental de vida, onde se busca de recursos para recompor e transformar em necessário o que se pode entender como desnecessário para o meio ambiente. Para isso, é importante a preservação de recursos naturais que sejam exemplos de recursos positivos para o meio ambiente.

Para Duarte (2002) "Hoje, virtualmente, todos os cidadãos de todos os cantos do planeta já ouviram falar, de alguma maneira, sobre a questão da preservação ambiental, concordando ou não com a sua importância." Ou seja, através das estratégias de comunicação que existem hoje, é possível defender ideias e conhecimento, fazendo com que os pensamentos e comportamentos de algumas pessoas mudem em relação a preservação do meio ambiente em que vivem.

Com isto, percebemos que a conscientização ambiental necessita do próprio indivíduo, com métodos educacionais e até mesmo legislativos, que beneficiam o processo 
Relatos de atividades de conscientização e educação ambiental sobre o destino correto dos resíduos sólidos em São Borja - RS

de conscientização através de avisos, artigos, e em relação ao legislativo até mesmo punições instituídas pelo Direito Ambiental.

\section{O PAPEL DA COMUNICAÇÃO NA CONSCIÊNCIA AMBIENTAL}

Segundo Andrade (2003), o papel das Relações Públicas funciona como um agente para o bom funcionamento de uma ação e a busca pela cidadania. Para entender a profissão e a atividades de Relações Públicas, é preciso ter o conhecimento sobre cidadania. Esse conjunto precisa ser realizado em prol de uma nova sociedade. Andrade pondera também que da mesma forma que a Publicidade e Propaganda funcionam juntas ao Marketing, as Relações Públicas atuam com a cidadania, focando o campo social. A consciência está se expandindo, pois é cada vez maior o número de informações que nos cerca, mas ainda assim a Comunicação enquanto meios e estratégicas é fundamental.

A dificuldade encontrada permeia-se nas poucas ações de conscientização que são realizadas na prática, apesar da função de cuidar do meio ambiente ser uma responsabilidade de todos. Essa conscientização não acontece efetivamente, podemos ver isso nas ruas e calçadas, um exemplo disso é quando chove as enchentes causadas por causa dos resíduos sólidos que entopem bueiros e saídas de água. Posto isso, a função da comunicação, antes de tudo, é aguçar uma mudança de valores e conduta do ser humano, conscientizando da mesma forma que vai informando, para que no fim, esse pensamento não fique apenas nisso e se transforme em ações. Sendo assim, podemos afirmar que o papel básico das Relações Públicas no âmbito da consciência social é criar uma ponte para a união entre as pessoas, através de informações coerentes, transformando-as em ações possíveis e viáveis. E ter em mente a consciência de todos os nossos atos como cidadão, no qual temos o dever de cuidar e preservar em meio a essa crise ambiental, sendo este o ponto de partida para um trabalho de comunicação para a proteção do meio ambiente.

\section{PLANOS DE EDUCAÇÃO AMBIENTAL NAS ESCOLAS}

As propostas de atividades de educação ambiental na gestão dos resíduos sólidos promovem a conscientização, através do processo participativo, no qual o aluno atua ativamente no diagnóstico dos problemas ambientais na busca de soluções. Foram 
Relatos de atividades de conscientização e educação ambiental sobre o destino correto dos resíduos sólidos em São Borja - RS

realizadas atividades interativas em quatro escolas públicas da cidade de São Borja (RS). Nas escolas, as atividades foram realizadas em estudantes entre a faixa etária de 08 a 18 anos, no local foi realizada a construção de uma composteira, para fins de incentivar a reutilização dos resíduos orgânicos, conscientizar e mostrar uma forma de aproveitamento dos resíduos orgânicos para propiciar uma melhora para o Meio Ambiente, bem como proteger o ambiente para produzir menos resíduos orgânicos. Isso permitirá a obtenção de um composto rico em nutrientes, natural e que podemos colocar em vasos e canteiros.

A construção da composteira foi realizada nas salas de aula das escolas com a utilização de três caixas empilhadas, duas com fundos furados, colocação de terra, minhoca e restos de resíduos orgânico rico em nitrogênio e misturá-lo a restos vegetais ricos em carbono, gerando um composto orgânico. A prática de compostagem é satisfatória do ponto de vista tecnológico, promove o aprendizado não somente de educação ambiental, mas sobre a cidadania, visando uma participação ativa dos órgãos e instituições públicas e privadas e da sociedade organizada.

Ao diminuirmos a quantidade de resíduos sólidos destinado aos aterros, haverá por consequência, uma economia nos custos de transporte e diminuição dos acúmulos de resíduos nos aterros sanitários. A técnica de compostagem promove também, a valorização de um insumo natural, ambientalmente seguro. $\mathrm{O}$ adubo orgânico atua sobre a reciclagem dos nutrientes do solo e no reaproveitamento agrícola da matéria orgânica, evitando assim, o uso de fertilizantes inorgânicos, proporcionando uma alimentação saudável e natural.

São Borja é uma cidade em que ainda há pouca conscientização por parte da população em relação à separação dos resíduos gerados, uma vez que a cidade não tem projeto de coleta seletiva, por isso, o incentivo de práticas de separação dos resíduos sólidos e orgânicos. Um cidadão são-borjense produz em média 1,5 kg de resíduos por dia, e a cidade de São Borja possui aproximadamente 63 mil habitantes. Desta forma, algumas atividades podem ser propostas, como construções de composteiras, separação dos resíduos sólidos, o que fazer e onde levar lâmpadas, pneus e lixo eletrônico, atividades com jogos educativos, caça-palavras, labirinto, pinturas, qual a lixeira para cada resíduo encontrado, incentivo à rios e córregos limpos. Os estudantes entre a faixa etária de 08 a 18 anos realizam as atividades com seriedade e levam os modelos aprendidos, como, exemplos a serem reproduzidos em casa. 
Relatos de atividades de conscientização e educação ambiental sobre o destino correto dos resíduos sólidos em São Borja - RS

\section{PRINCIPAIS AÇÕES REALIZADAS NO PROJETO}

Foram várias dimensões trabalhadas no projeto, todas no sentido de se completarem e levarem ao objetivo central. O eixo era discutir e agir sobre a destinação correta dos resíduos. As ações foram realizadas a partir do projeto de extensão - O Lixo em São Borja: debatendo e agindo, da Universidade Federal do Pampa - UNIPAMPA e realizado em parceria com o curso de Bacharelado em Gestão Ambiental da Universidade Estadual do Rio Grande do Sul - UERGS, campus São Borja.

Segundo Santos (2004, p. 73), a extensão universitária pode estar "na luta contra a exclusão social e a degradação ambiental, na defesa da diversidade cultural". Por isto, a escolha do projeto em uma das estratégias foi ir para as escolas. Professores e alunos podem ser multiplicadores em seus espaços sociais, o que amplia o leque de impacto do projeto aqui descrito.

\section{Blitze}

Em julho de 2016, foram realizadas blitz̧e na praça XV de novembro, com entrega de fôlderes aos motoristas que cruzavam pelas ruas centrais da cidade. Foi realizada uma ação de conscientização sobre o lixo produzido no dia-a-dia, sendo distribuídos saquinhos de lixos para carros e fôlderes que tratam e destacam com mais ênfase sobre a separação e destinação correta para os diferentes tipos de resíduos sólidos.

\section{Estratégias de Comunicação}

Foram confeccionadas 50 camisetas para representar o projeto em ações realizadas na cidade, assim como nos eventos organizados pelo projeto. Além dos integrantes da equipe do projeto, em escolas e nos eventos, algumas eram sorteadas.

Foi criada uma fanpage ${ }^{1}$ no facebook, com 462 curtidas, como meio de comunicação, divulgação e acessibilidade para melhor repercussão das atividades, eventos e informações práticas e de interesse público.

Fôlderes foram elaborados com o intuito de serem divulgados à comunidade, nas praças da cidade, em blitz̧e nas escolas. Com design colorido e atraente aos olhos de quem o vê, o que busca mais interesse dos jovens sobre o assunto, com informações locais sobre o destino correto do lixo produzido em casa e a criação de composteiras, com três mil unidades impressas.

${ }^{1}$ Disponível em: <https://www.facebook.com/debatendoeagindo>. Acesso em: 21 set. 2017. 
Relatos de atividades de conscientização e educação ambiental sobre o destino correto dos resíduos sólidos em São Borja - RS

Além disto, foram utilizadas outras estratégias, como envio de releases para os meios de comunicação sobre a temática, bem como dos eventos a realizados, e entrevistas concedidas às emissoras de rádio da cidade, com mensuração dos mesmos.

\section{Mutirão de limpeza nas margens do rio e em ruas críticas da cidade}

Além disto, foi realizado em parceria com os professores e acadêmicos do curso de Bacharelado em Gestão Ambiental da Universidade Estadual do Rio Grande do Sul, um mutirão de limpeza através do recolhimento de lixos nas ruas, na área central da cidade de São Borja e nas margens do Rio Uruguai, com o apoio da secretaria Municipal do Meio Ambiente, $2^{\circ}$ RCMec. O impacto da conscientização foi atingido, quando foram recolhidas cinco caçambas de resíduos sólidos (lixo), do tipo eletrônico, restos de construção, mobília de casa, roupas, garrafas pet e vários plásticos foram retirados das margens das ruas e do rio, transformando áreas com muito lixo espalhado em locais visualmente mais limpos. $\mathrm{Na}$ semana do Meio Ambiente o grupo participou ainda da inauguração de lixeiras que foram instaladas na praça XV de novembro em São Borja. Foram distribuídas mudas de árvores frutíferas, além de música ao vivo com artistas locais, distribuição de erva mate, exposição de artesanatos à base de materiais recicláveis e pontos de coleta para lâmpadas e lixos eletrônicos. Os acadêmicos do curso de Bacharelado em Gestão Ambiental da UERGS demonstraram a construção de composteiras caseiras e a destinação dos resíduos em lixeiras adequadas.

\section{Palestras educativas em escolas}

Outra etapa importante do trabalho foi a realizações de palestras educativas com a coordenadora do curso de gestão ambiental da UERGS, professora Saionara Salomoni em quatro escolas municipais e estaduais - para alunos do ensino fundamental ( $6^{\circ}$ ao $9^{\circ}$ ano) e do ensino médio - com informações sobre destinação do lixo, como realizar a construção de composteiras domésticas, ressaltando a importância do destino correto aos resíduos sólidos e jogos educativos sobre os resíduos sólidos o que permitiu a interação com os alunos. 
Relatos de atividades de conscientização e educação ambiental sobre o destino correto dos resíduos sólidos em São Borja - RS

\section{Enfeites natalinos com garrafas pet}

O projeto também fez uma parceria com a CDL e o SINDILOJAS ${ }^{2}$ que proporcionou um curso gratuito pelo SENAC para a elaboração de enfeites natalinos em São Borja com garrafas pet. A ação funcionava da seguinte forma: o projeto tinha pontos de coleta em diferentes locais da cidade e trabalhou para que tivesse matéria-prima para a elaboração dos enfeites. Estima-se que mais de 50 mil garrafas pet foram utilizadas na produção. Foi uma ideia piloto e devido ao sucesso, as entidades mencionadas já estão realizando a continuidade do mesmo.

\section{Reconhecimento ao trabalho dos garis}

Para fechar a edição do projeto e como forma de reconhecer o importante trabalho dos garis, eles foram reunidos em dezembro em uma ação e feito um agradecimento pelos organizadores do projeto pelo trabalho realizado e pouco visível e entregue uma cesta natalina, conseguida através de patrocínio. Ao total foram doze garis, sendo a maioria senegaleses (sete).

\section{CONSIDERAÇÕES FINAIS}

Falar de resíduos sólidos é falar de vários desafios que necessitam ser superados, e se torna essencial a ajuda de pelo menos uma parcela significativa da sociedade. Por isso que umas das estratégias centrais do projeto foi a elaboração do fôlder que continha as informações da destinação correta dos diferentes tipos de resíduos, com telefones e endereços para auxiliar na prática desta ação. Assim como se apresenta na Lei no 12.305 de 02 de agosto de 2010, que institui a Política Nacional de Resíduos Sólidos no Brasil, e o planejamento dos resíduos sólidos deve atender tanto os aspectos sanitários e econômicos, quanto os aspectos ambientais e sociais. A temática inerente aos impactos ambientais causados pelos resíduos sólidos, como os demais problemas ambientais, tornou-se uma questão que excede à capacidade dos órgãos governamentais e necessita da participação da sociedade para sua solução.

Então, é de suma importância incentivar a mudança para novos hábitos para população, e o projeto de extensão teve como uma de suas principais ações fazer

\footnotetext{
${ }^{2}$ Mais informações disponíveis em: <goo.gl/BW8BXv> Acesso em: 21 set. 2017.
} 
Relatos de atividades de conscientização e educação ambiental sobre o destino correto dos resíduos sólidos em São Borja - RS

exatamente isso, incentivar essa conscientização, como ponto de partida. A sociedade deve ter em mente que o lixo é responsabilidade de todos, sem exceção, e recusar embalagens que muitas vezes não são necessárias, evita o desperdício de muitos elementos.

Somente com estratégias de assessoria de imprensa - foram alcançadas sete veiculações de matérias em jornais locais sobre o projeto (Folha de São Borja e O Regional), sem contar as entrevistas nas emissoras de rádio. Isto, ampliado com a distribuição dos três mil fôlderes, mais a atuação nos eventos e ações em praças e ruas, palestras nas quatro escolas, mostram o resultado em termos quantitativos, de público atingido com o projeto, que estima-se tenha sido em torno de 12 mil pessoas.

Podemos afirmar que os objetivos de fazer a sociedade mais consciente das suas atitudes em relação aos resíduos não é algo tão simples, mas adotando ações que o projeto disseminou irá ajudar a comunidade são-borjense neste processo. Espera-se que depois deste, as perspectivas de novas atitudes em relação aos cuidados que devemos ter com o lixo possam se expandir e envolver cada vez mais as pessoas com o mesmo propósito.

A proposta das duas Universidades envolvidas no projeto (UNIPAMPA e UERGS) foi de demonstrar como os moradores da cidade podem destinar o lixo para locais adequados, evitando que eles sejam jogados em qualquer lugar com prejuízos ao ambiente. As atividades realizadas serviram para conscientizar as pessoas, das necessidades de mudanças dos nossos hábitos de vida diários, assumindo assim, uma postura de responsabilidade ambiental.

\section{REFERÊNCIAS}

ANDRADE, C. T. S. Curso de Relações Públicas: relações com os diferentes públicos. 6. ed. São Paulo: Pioneira, 2003.

DUARTE, Lúcia. Ética ambiental e comunicação: considerações pragmáticas. In. Freitas, Ricardo F. Lucas, Luciane (org). Desafios contemporâneos em Comunicação: Perspectivas de Relações Públicas. São Paulo: Summus, 2002.

FREIRE, Paulo. Conscientização. São Paulo: Moraes, 1980.

GARCÍA, José Sixto. Comunicação Ambiental para o século XXI. Espanha, 2009.

LEONTIEV, A. N. Atividade e Consciência. Lisboa: Livros Horizontes, 1980. 
Relatos de atividades de conscientização e educação ambiental sobre o destino correto dos resíduos sólidos em São Borja - RS

LOUREIRO, C. F.; LAYRARGUES, P. P.; CASTRO, R. S. (orgs.). Repensar a educação ambiental: um olhar crítico. São Paulo: Cortez, 2009.

PRESIDÊNCIA DA REPÚBLICA. Lei no 12.305 de 02 de agosto de 2010. Disponível em:<http://www.planalto.gov.br/ccivil_03/_ato2007-2010/2010/lei/112305.htm>. Acesso em: 05 dez. 2016.

SANTOS, Boaventura de Sousa. A Universidade no Século XXI: Para uma Reforma Democrática e Emancipatória da Universidade, Cortez Editora, São Paulo, Coleção Questões da Nossa Época, 2004. 